\title{
Determinação das emissões de dióxido de carbono das matérias primas do concreto produzido na região norte do Rio Grande do Sul
}

\author{
Determination of the carbon dioxide emissions of raw \\ materials used in the production of concrete in the \\ northern region of the state of Rio Grande do Sul, Brazil
}

\section{Jair Frederico Santoro Moacir Kripka}

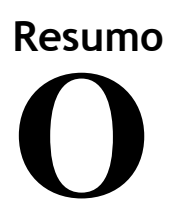

concreto é um dos materiais mais usados na construção civil no Brasil, e seu uso difundido advém da grande facilidade de execução e adaptação às mais diversas formas. Reduzir o consumo dos materiais envolvidos na produção do concreto é uma das maneiras de buscar uma maior sustentabilidade da construção civil. Estas reduções de consumo de materiais, se avaliadas levando-se em conta também os impactos que a produção e o transporte dos mesmos geram no meio ambiente, podem vir a aprimorar ou redirecionar as conclusões ou decisões a serem tomadas em relação à busca de uma maior sustentabilidade ambiental. Dentro deste enfoque foram levantadas e avaliadas as emissões de dióxido de carbono $\left(\mathrm{CO}_{2}\right)$, impactos ambientais gerados quando da extração/produção e transporte até o local de utilização das matérias primas do concreto. Juntamente foram levantadas e avaliadas as emissões na produção e transporte do concreto até a obra. Dentre as conclusões do estudo constatou-se que menores resistências características do concreto produzirão menores emissões de $\mathrm{CO}_{2}$, e que a influência do transporte nas emissões é significativa devido às longas distâncias percorridas pela maior parte das matérias primas.

Palavras-chaves: Concreto. Emissões de $\mathrm{CO}_{2}$. Matérias primas. Extração. Produção. Transporte.

\begin{abstract}
Concrete is one of the most widely used materials in the Brazilian construction industry. This widespread use is mainly due to the easiness of implementation and adaptation to various forms. The reduction of the consumption of materials involved in the production of concrete is one way to achieve more sustainable construction. These reductions, if evaluated taking into account also the impacts that the production generates in the environment, are likely to enhance or redirect the conclusions or decisions to be made regarding the quest for greater environmental sustainability. With this objective in mind, the carbon dioxide $\left(\mathrm{CO}_{2}\right)$ emissions and the environmental impacts of the production of concrete were evaluated, considering the extraction and production of materials (binder, coarse aggregates, fine aggregates and steel) used in the northern region of Rio Grande do Sul state, Brazil. One of the conclusions of the study was that lower strength concrete produces lower $\mathrm{CO}_{2}$ emissions, and that the influence of transport emissions is significant due to the long distances that most of the raw materials must cover.
\end{abstract}

Universidade de Passo Fundo

Recebido em 01/03/15 Passo Fundo - RS - Brasi Aceito em 24/11/15

Jair Frederico Santoro

Moacir Kripka

Keywords: Con
Transportation 


\section{Introdução}

A preocupação de toda a sociedade com a crescente redução dos recursos naturais e com a degradação progressiva do meio ambiente vem se ampliando nos últimos anos. Esta consciência ecológica em franco crescimento, seja espontaneamente ou por força da legislação, tem feito com que surjam novas técnicas de análise que buscam auxiliar a construção de modelos de avaliação ambientalmente mais sustentáveis, ou seja, que minimizem os impactos produzidos no meio ambiente.

Segundo John, Oliveira e Lima (2007), os impactos ambientais do fluxo de materiais na produção do ambiente construído são evidentes, sendo que a construção de edificações consome até $75 \%$ dos recursos extraídos da natureza, com o agravante que a maior parte destes recursos não é renovável. A extração, produção, transporte e utilização dos materiais contribuem de forma significativa para a poluição do planeta.

Embora a construção de edifícios traga inegáveis benefícios à comunidade, também está associada a altos custos em termos de impactos ambientais, os quais podem ser medidos, entre outros, pelo consumo de recursos naturais, energia, emissão de gases do efeito estufa e geração de resíduos. A adoção de procedimentos e estratégias para minimizar esses impactos necessitará uma mudança nas atitudes e na cultura dos construtores e de todos os demais envolvidos no processo (PULLEN et al, 2012).

O concreto é o principal material de construção do mundo (EDVARDSEN; TOLLOSE, 2001). No Brasil, a situação não é diferente, devendo-se a diversos fatores, muitos deles intrínsecos à realidade do país, dos quais se destacam a pouca qualificação da mão de obra e a ampla disponibilidade dos insumos. Além disso, possui características interessantes como facilidade de se moldar às mais diversas formas e resistência ao fogo.

Em 2010, de acordo com dados da International Cement Review, a produção mundial de cimento atingiu cerca de 3,3 bilhões de toneladas anuais, um incremento de mais de $100 \%$ em cerca de 10 anos, aumentando ainda mais os impactos gerados ao meio ambiente (INTERCEMENT, 2015). Carvalho (2008) refere-se a impactos ambientais nas fases de produção do cimento, desde a extração da matéria prima com vibrações do terreno e consequentes desmoronamentos e erosões, emissões gasosas com poluição do ar, cavas abandonadas com desmoronamentos e erosões, até a produção do cimento e clinquerização com emissões de gases como o dióxido de carbono $\left(\mathrm{CO}_{2}\right)$, dióxido de enxofre $\left(\mathrm{SO}_{2}\right)$, monóxido de carbono (CO), gases oxidantes, óxidos nitrogenados e compostos de chumbo que geram aquecimento global e poluição do ar.

Já Oliveira (2007) relata que a questão das emissões associadas à produção do clínquer é um dos principais componentes da pegada carbônica da construção, indicando que cerca de $6 \%$ do dióxido de carbono $\left(\mathrm{CO}_{2}\right)$ gerado no Brasil seja oriundo da descarbonatação do calcário que ocorre durante a produção de cimento.

A areia utilizada nas edificações apresenta significativa demanda por recursos renováveis, como água, nas etapas de extração e beneficiamento, mas também é possível perceber, com o auxílio da Tabela 1, que são responsáveis pelas maiores quantidades de emissões atmosféricas (44\% cada uma). Verifica-se que 99,8\% das emissões atmosféricas são oriundas do dióxido de carbono, o $\mathrm{CO}_{2}$, o qual, embora não afete diretamente a saúde humana, é um dos gases causadores do aquecimento global à acentuação do efeito estufa.

Os impactos produzidos na cadeia da construção civil podem ser avaliados através da análise do ciclo de vida da estrutura ou de um material empregado na construção, conhecida usualmente como ACV. Segundo a NBR 14040 (ABNT, 2009, p. 2), ACV é a "[...] compilação e avaliação das entradas, das saídas e dos impactos ambientais potenciais de um sistema de produto ao longo do seu ciclo de vida [...]", onde as entradas e saídas são designadas em termos de materiais e energia. Buscando viabilizar o comparativo entre estudos de impacto de diferentes produtos, devem ser observadas as normas que estipulam os indicadores ambientais a utilizar. Indicadores são os itens que permitem mensurar os impactos, com base nos aspectos ambiental, social e econômico. Com relação ao aspecto ambiental, esses indicadores podem ser, por exemplo, o potencial de destruição da camada de ozônio ou o potencial de acidificação da terra e dos aquíferos. Várias são as ferramentas disponíveis para análise do ciclo de vida, as quais devem ser alimentadas através de um banco de dados relativo à região em análise. Podem ser consideradas as fases de pré-uso (englobando transporte, fabricação dos materiais da construção e a construção em si), de uso (aquecimento, ventilação, manutenção, uso de água, geração de resíduos) e de pós-uso (demolição e reciclagem). 
Tabela 1 - Emissões atmosféricas totais nas etapas de ciclo de vida da areia para construção civil

\begin{tabular}{|c|c|c|c|c|c|}
\hline Emissões atmosf. & Atividade 1 & Atividade 2 & Atividade 3 & Atividade 4 & Total \\
\hline & \multicolumn{5}{|c|}{$\mathrm{Kg} \cdot \mathrm{m}^{-3}$ de areia } \\
\hline $\mathrm{C}_{\mathrm{x}} \mathrm{H}_{\mathrm{y}}$ & $0,48 \mathrm{E}-04$ & $0,48 \mathrm{E}-04$ & $0,72 \mathrm{E}-05$ & $0,28 \mathrm{E}-02$ & $0,29 \mathrm{E}-02$ \\
\hline $\mathrm{CO}$ & $0,12 \mathrm{E}-02$ & $0,12 \mathrm{E}-02$ & $0,18 \mathrm{E}-03$ & $0,23 \mathrm{E}-02$ & $0,49 \mathrm{E}-02$ \\
\hline $\mathrm{NO}_{\mathrm{x}}$ & $0,14 \mathrm{E}-02$ & $0,14 \mathrm{E}-02$ & $0,21 \mathrm{E}-03$ & 1,04E-02 & $0,13 \mathrm{E}-01$ \\
\hline MP & $0,24 \mathrm{E}-03$ & $0,24 \mathrm{E}-03$ & $0,24 \mathrm{E}-03$ & $0,81 \mathrm{E}-02$ & $0,48 \mathrm{E}-03$ \\
\hline $\mathrm{SO}_{\mathrm{x}}$ & $0,47 \mathrm{E}-03$ & $0,47 \mathrm{E}-03$ & $0,36 \mathrm{E}-04$ & $0,17 \mathrm{E}-02$ & $0,26 \mathrm{E}-02$ \\
\hline $\mathrm{CH}_{4}$ & $0,60 \mathrm{E}-05$ & $0,60 \mathrm{E}-05$ & $0,90 \mathrm{E}-06$ & 0 & 0,13E-04 \\
\hline $\mathrm{N}_{2} \mathrm{O}$ & $0,26 \mathrm{E}-04$ & $0,26 \mathrm{E}-04$ & $0,40 \mathrm{E}-05$ & $0,88 \mathrm{E}-05$ & $0,65 \mathrm{E}-04$ \\
\hline $\mathrm{CO}_{2}$ & $0,52 \mathrm{E}+01$ & $0,52 \mathrm{E}+01$ & $0,08 \mathrm{E}+01$ & $0,06 \mathrm{E}+01$ & 11,8 \\
\hline Total & 5,20 & 5,20 & 0,80 & 0,62 & 11,82 \\
\hline
\end{tabular}

Fonte: Souza (2012).

Nota: Atividade 1 - Extração; Atividade 2 - Beneficiamento; Atividade 3 - Armazenagem; e Atividade 4 - Transporte.

Diversos estudos vêm sendo desenvolvidos com o objetivo de identificar o impacto relativo dos materiais estruturais, comparando construções em concreto, aço e madeira, com exemplos em Passer et al. (2007), Guardigli, Monari e Bragadin (2011), Alshamrani, Galal e Alkass (2014) e em Takano et al. (2014). Observa-se que, de forma geral, os resultados de comparações dessa natureza nem sempre são conclusivos ou mesmo coincidentes. Segundo Cabeza et al. (2014), é difícil comparar os diferentes estudos devido a particularidades, por exemplo, no tipo de edificação, clima, exigências de conforto e normas locais. Já Hammond e Jones (2008), os quais desenvolveram uma extensa base de dados para os principais materiais empregados na construção no Reino Unido, considerando tanto energia como emissão de dióxido de carbono, destacam que a escolha de um único número para representar um material ou produto requer uma análise cuidadosa, por parte do profissional, tanto da fonte dos dados como das considerações efetuadas para sua obtenção.

Especificamente para o concreto, várias pesquisas têm sido efetuadas no sentido de determinar parâmetros de projeto que reduzam o impacto das estruturas, medido usualmente em termos de emissão de energia, de dióxido de carbono, ou do potencial de aquecimento global. Exemplificando, destacam-se os estudos de Paya-Zaforteza et al. (2009), Ochsendorf et al. (2011), Yeo e Gabbai (2011), Miller et al. (2013), Ji, Hong e Park (2014) e de Medeiros e Kripka (2014).

Os artigos que consideram a construção como um todo geralmente levam em conta todas as fases da $\mathrm{ACV}$, enquanto os estudos que consideram apenas os materiais geralmente focam-se na etapa de produção desses materiais. De forma geral observa-se, a partir das referências analisadas, que existem grandes variações nos valores de emissão obtidos. Exemplificando, para um concreto de resistência característica de $40 \mathrm{MPa}, \mathrm{Ji}$, Hong e Park (2014) consideraram, a partir de valores do Instituto de Tecnologia da Construção da Coreia do Sul, uma emissão de dióxido de carbono de 340 $\mathrm{KgCO}_{2} / \mathrm{m}^{3}$ obtida por regressão, uma vez que os valores de referência são fornecidos para uma única classe de concreto. Já o Instituto de Tecnologia da Construção da Catalunha, Espanha, considera para a mesma resistência característica a emissão de $143,77 \quad \mathrm{KgCO}_{2} / \mathrm{m}^{3}$ de concreto, sem levar em conta as emissões relativas ao transporte (PAYA-ZAFORTEZA et al., 2009). As grandes diferenças observadas entre as diversas fontes estão de acordo com resultados apontados pela National Ready Mixed Concrete Association (2008), segundo os quais a emissão de dióxido de carbono normalmente varia entre 100 e 300 $\mathrm{KgCO}_{2} / \mathrm{m}^{3}$ de concreto, dependendo do traço empregado. Pommer e Pade (2005) destacam que a matriz energética é outro fator que influencia diretamente nas emissões, daí a necessidade de se conhecer a priori o local de produção. Para os países europeus, a emissão média de dióxido de carbono para a produção de $1 \mathrm{~kW} / \mathrm{h}$ de energia era de $0,475 \mathrm{~kg} / \mathrm{CO}_{2}$, variando entre zero para a Noruega, onde a base é a energia hidrelétrica, e $0,753 \mathrm{~kg} / \mathrm{CO}_{2}$ na Dinamarca, onde o carvão é a principal fonte de geração de energia (POMMER; PADE, 2005).

Sendo assim, em função da necessidade de se conhecer valores específicos que subsidiem a análise dos impactos de forma mais precisa, o presente estudo buscou determinar as emissões de dióxido de carbono geradas nas etapas de extração, produção e transporte das matérias primas utilizadas na produção do concreto, bem como as da fase de produção e transporte do concreto até a obra, na região norte do Rio Grande do Sul, 
considerando dados levantados ao longo do ano de 2014 e no primeiro trimestre de 2015. Com esta finalidade, foram utilizados dados obtidos de uma das principais centrais dosadoras da cidade de Passo Fundo.

\section{Levantamentos das emissões de $\mathrm{CO}_{2}$ na produção e transporte das matérias primas e na produção e transporte do concreto até a obra}

As necessidades de construção civil continuam sempre em crescimento constante. O déficit habitacional, as ampliações e reformas demandam cada vez mais matérias primas como agregado graúdo, miúdo e aglomerante, pois as mesmas fazem parte da produção de vários materiais utilizados na construção civil e, dentre eles, o concreto. O transporte destas matérias primas é outro aspecto considerável, visto a maioria delas ser de origem mineral. Conforme Aguirre e Hennies (2010), o transporte é necessário sempre que o local de origem é diferente do local de consumo ou destino, sendo este conceito muito forte quando se tratar de mineração, devido à ocorrência das rochas e minérios se dar pelo capricho da natureza e não em local definido através de estudos matemáticos, financeiros e de planejamento estratégico. Daí os transportes serem significativos e merecedores de consideração e atenção especial.

Nos levantamentos realizados para o desenvolvimento do presente estudo foi considerada a emissão de $\mathrm{CO}_{2}$ da combustão do diesel, um dos elementos de utilização primordial nos processos de extração, produção e transporte das matérias primas, pois a maioria das etapas demanda transportes e movimentações com a utilização de equipamentos onde o diesel é o combustível preponderante. A emissão de $\mathrm{CO}_{2}$ do processo de combustão da gasolina aditivada, utilizada nos veículos de apoio nas empresas envolvidas no processo, também foi considerada.
A emissão de $\mathrm{CO} 2$ do processo de combustão do diesel e da gasolina aditivada utilizados neste estudo é proveniente do Primeiro Inventário Nacional de Emissões Atmosféricas por Veículos Automotores Rodoviários (BRASIL, 2011). Os fatores de emissão de $\mathrm{CO}_{2}$ utilizados neste Inventário foram baseados nos fatores de emissão apresentados no Primeiro Inventário Brasileiro de Emissões Antrópicas de Gases de Efeito Estufa (Relatório de Referência: Emissões de Dióxido de Carbono por Queima de Combustíveis: Abordagem Top-Down). Tais fatores foram convertidos da unidade original, em $\mathrm{kg} / \mathrm{TJ}$, para $\mathrm{kg} / \mathrm{L}$ ou $\mathrm{kg} / \mathrm{m} 3$, aplicando-se os fatores de conversão e os valores de densidade energética dos combustíveis apresentados no Balanço Energético Nacional 2010 (BRASIL, 2011).

Este inventário apresenta como fator de emissão o valor de:
(a) 2,671 $\mathrm{Kg}$ de $\mathrm{CO}_{2}$ para cada litro de Diesel consumido; $\mathrm{e}$

\section{(b) 2,269 $\mathrm{Kg}$ de $\mathrm{CO}_{2}$ para cada litro de Gasolina} Aditivada consumida.

Em virtude da dificuldade de acesso às áreas produtoras do aglomerante utilizado na produção do concreto, os valores de emissão de $\mathrm{CO}_{2}$ dos processos produtivos foram provenientes de referências bibliográficas o que, segundo levantamentos efetuados pelos autores, deve acarretar pouca influência nos resultados obtidos.

As emissões provenientes dos transportes destas matérias primas foram calculadas considerando as distâncias dos mesmos até o local de utilização, conforme localizações geográficas apresentadas na Figura 1.

Os levantamentos de dados dos processos de extração, produção e transporte das matérias primas utilizadas na produção do concreto, considerou as distâncias e o fluxograma apresentado na Figura 2, para os atuais fornecedores da central dosadora. 
Figura 1 - Localização geográfica das matérias primas

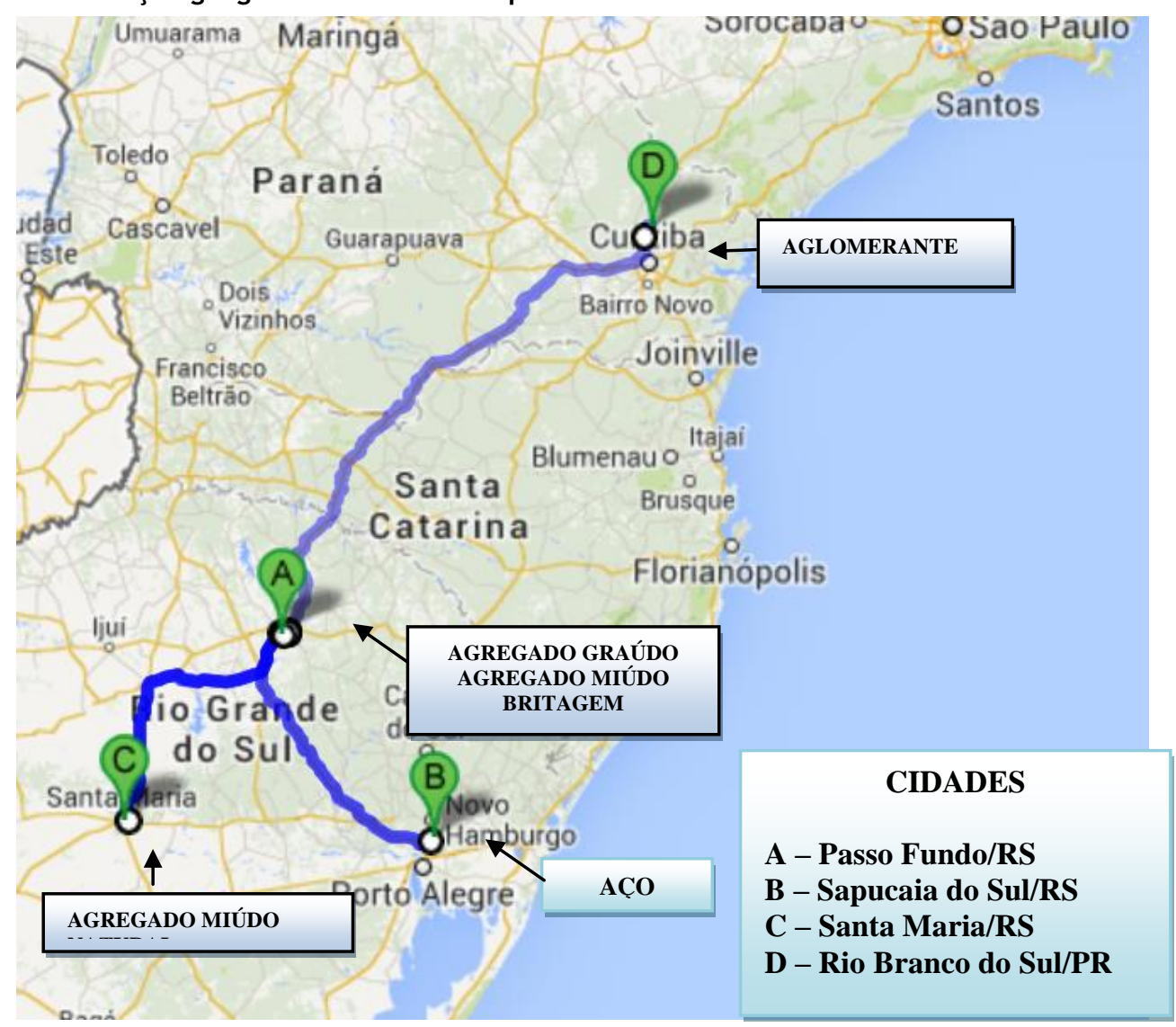

Fonte: Google Maps (2015).

Figura 2 - Regiões de levantamento de dados

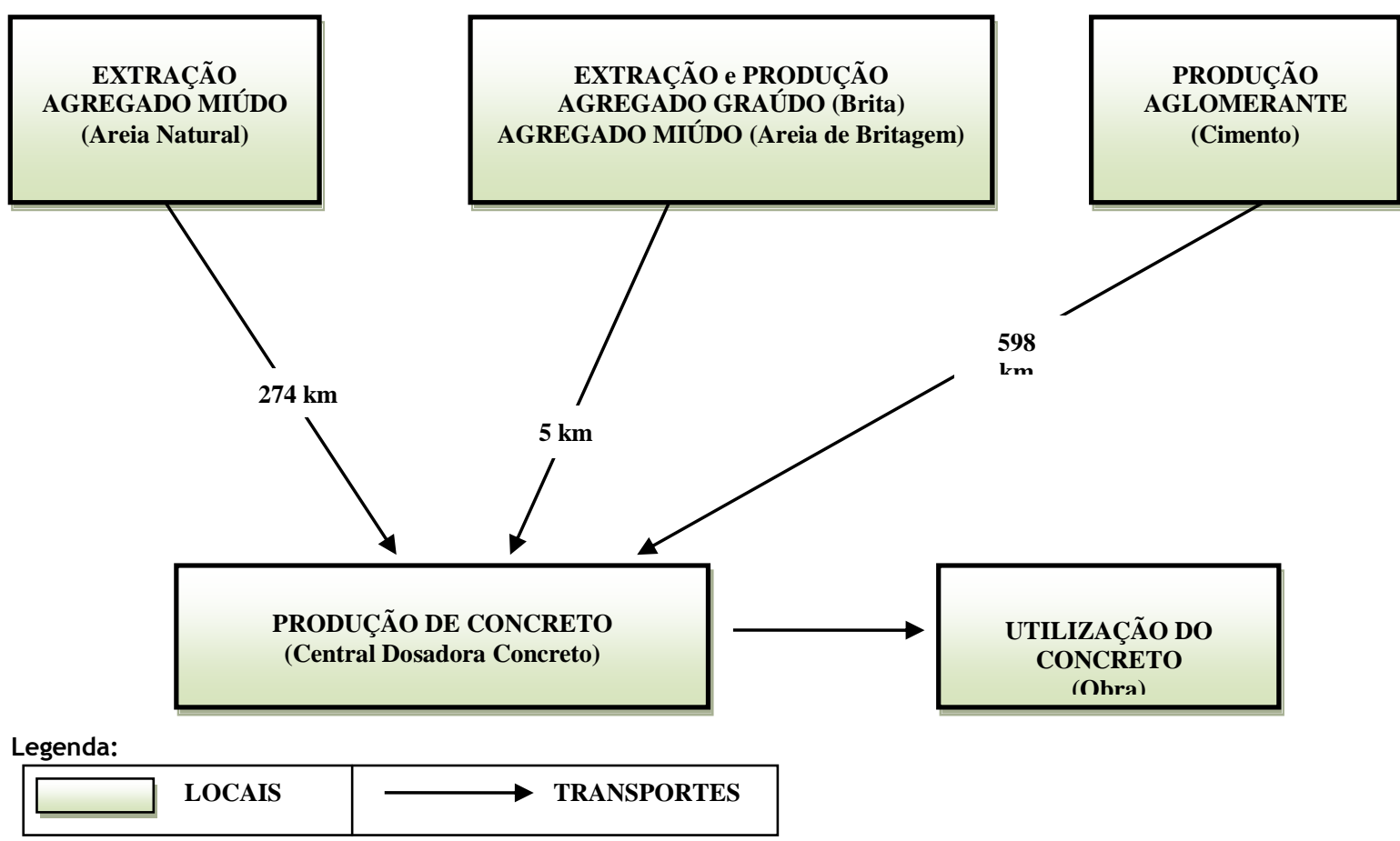




\section{Emissões $\mathrm{CO}_{2}$ na produção e transporte do agregado graúdo (brita) e miúdo (areia de britagem)}

O levantamento considerou as atividades utilizadas no processo de extração, produção, armazenamento e transporte até a central dosadora de concreto, do agregado graúdo (brita) e miúdo (areia de britagem) da mineradora. $\mathrm{O}$ processo de extração da matéria prima, neste estudo basalto, inicia com a limpeza e perfuração do topo da jazida por uma perfuratriz, retirada da umidade nas perfurações e inserção dos explosivos nas mesmas. Após são realizadas as detonações dos explosivos, desprendendo as rochas de basalto da jazida, rochas que serão carregadas e transportadas até a central de britagem da mineradora. Chegando à central de britagem, as rochas de basalto são descarregadas no britador primário tipo mandíbula, onde sofrem a primeira quebra. Quebradas em tamanhos menores as pedras de basalto caem em correias transportadoras que as levam até o britador secundário e terciário os dois do tipo cônico. Com estas novas fragmentações e também com a passagem por peneiras classificatórias com malhas padronizadas são produzidos os agregados nas granulometrias normatizadas. A foto da Figura 3 apresenta uma visão geral do processo de britagem desenvolvido segundo o processo descrito, na central de britagem considerada no presente estudo.

Estando com as dimensões desejadas, os agregados graúdos e miúdos são armazenados para posterior carregamento em caminhões, pesagem e transporte até a central dosadora de concreto ou a outros clientes da mineradora.

No processo produtivo da mineradora em estudo, verificou-se a existência de perfuratriz, carregadeiras e caminhões que são utilizados na extração e movimentação dos agregados, sendo que tais máquinas utilizam diesel como combustível.

Após várias visitas para conhecimento do processo produtivo e questionamentos dos responsáveis da mineradora, foram obtidas as informações necessárias para a definição da emissão de $\mathrm{CO}_{2}$, informações estas apresentadas na Tabela 2, de maneira sintetizada.

Também foram informados, por parte dos responsáveis da mineradora, dados sobre o transporte do agregado graúdo e miúdo da mineradora até a Central Dosadora de Concreto, e partir destes dados, foram realizados os cálculos de emissão de $\mathrm{CO}_{2}$ no transporte do Agregado Graúdo e Miúdo até a Central Dosadora de Concreto, conforme Tabela 3.

\section{Emissões $\mathrm{CO}_{2}$ na produção e transporte do agregado miúdo (areia natural)}

O levantamento considerou as atividades utilizadas no processo de extração, produção, armazenamento e transporte até a central dosadora de concreto, do agregado miúdo (areia natural) da mineradora.

O processo de extração inicia com a dragagem da jazida, conforme ilustra a Figura 4, de onde é retirada a matéria prima do estudo, sendo a mesma armazenada ao lado da jazida para o processo de secagem natural. Após o processo de secagem a matéria prima é carregada e levada até o local de armazenamento final, onde são realizados os processos de medições ou pesagens, para posterior liberação aos clientes.

Figura 3 - Visão geral do processo de produção dos agregados

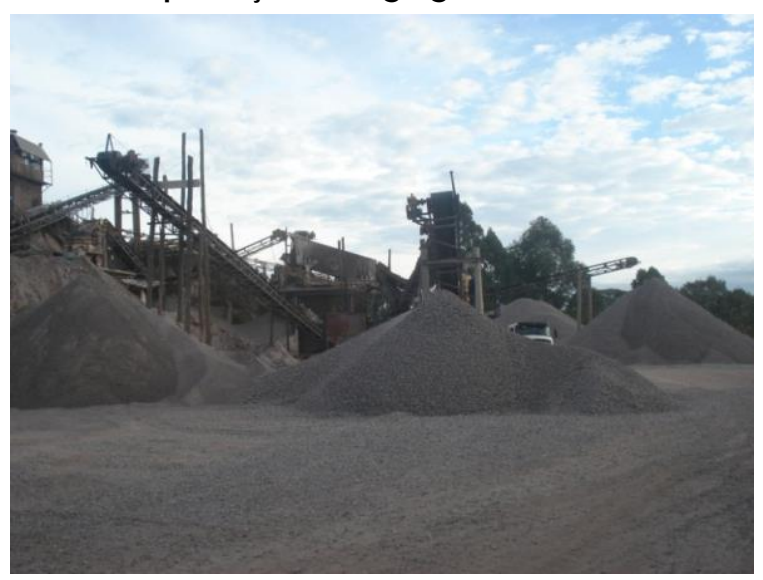

40 Santoro, J. F.; Kripka, M. 
Tabela 2 - Cálculo das emissões de $\mathrm{CO}_{2}$ das matérias primas no processo produtivo da mineradora

\begin{tabular}{c|c|c|c|c|c}
\hline Matéria Prima & $\begin{array}{c}\text { Produção } \\
(\mathbf{k g} / \mathbf{m e ̂ s})\end{array}$ & $\begin{array}{c}\text { Consumo } \\
\text { Diesel } \\
(\mathbf{l} / \mathbf{m e ̂ s})\end{array}$ & $\begin{array}{c}\text { Consumo } \\
\text { Diesel } \\
(\mathbf{l} / \mathbf{k g})\end{array}$ & $\begin{array}{c}\text { Emissão CO } \\
\text { Diesel } \\
(\mathbf{k g C O} / \mathbf{l})\end{array}$ & $\begin{array}{c}\text { Emissão } \\
\mathbf{C O}_{\mathbf{2}} \\
(\mathbf{k g C O} / \mathbf{k g})\end{array}$ \\
\hline $\begin{array}{c}\text { Agregado Graúdo e Miúdo } \\
\text { (brita e areia de britagem) }\end{array}$ & 10.000 .000 & 15.000 & 0,001500 & 2,671 & 0,004007 \\
\hline
\end{tabular}

Tabela 3 - Cálculo das emissões de $\mathrm{CO}_{2}$ do transporte das matérias primas

\begin{tabular}{c|c|c|c|c|c}
\hline Matéria Prima & $\begin{array}{c}\text { Carga } \\
(\mathbf{k g} / \text { viagem) }\end{array}$ & $\begin{array}{c}\text { Consumo } \\
\text { Diesel } \\
(\mathbf{l} / \mathbf{v i a g e m})\end{array}$ & $\begin{array}{c}\text { Consumo } \\
\text { Diesel } \\
(\mathbf{l} / \mathbf{k g})\end{array}$ & $\begin{array}{c}\text { Emissão CO } \\
\text { Diesel } \\
(\mathbf{k g C O} / \mathbf{l})\end{array}$ & $\begin{array}{c}\text { Emissão } \\
\mathbf{C O}_{2} \\
(\mathbf{k g C O} / \mathbf{k g})\end{array}$ \\
\hline Agregado Graúdo (brita) & 23.000 & 5 & 0,000217 & 2,671 & 0,000580 \\
\hline Agregado Miúdo (areia britagem) & 21.000 & 5 & 0,000238 & 2,671 & 0,000636 \\
\hline
\end{tabular}

Figura 4 - Dragagem da jazida

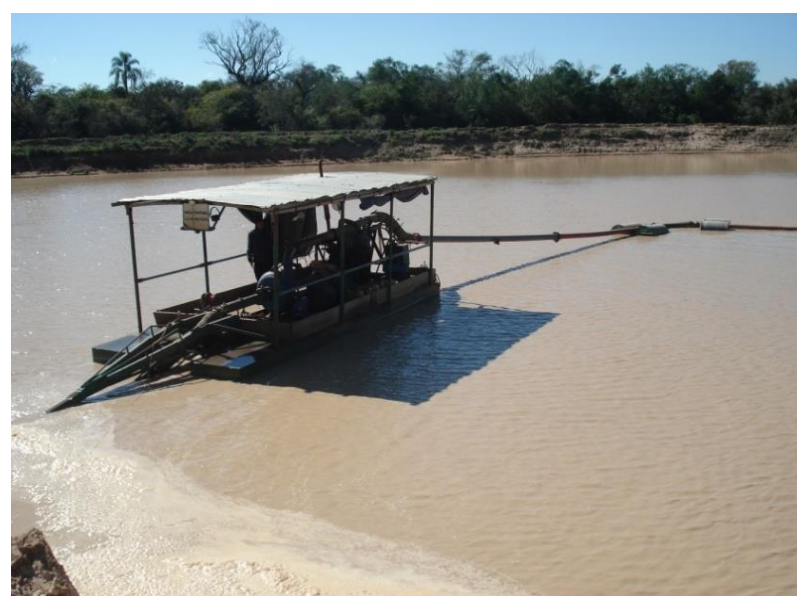

No processo produtivo da mineradora em estudo, verificou-se a existência de dragas, carregadeiras e caminhões que são utilizados na extração e movimentação do agregado miúdo natural, sendo que tais máquinas utilizam diesel como combustível.

Após os levantamentos realizados e com as informações necessárias para a definição da emissão de $\mathrm{CO}_{2}$, obteve-se o valor apresentado na Tabela 4.

Também foram levantados os dados em relação ao transporte do agregado miúdo (areia natural) até a Central Dosadora de Concreto, conforme Tabela 5.

\section{Emissões $\mathrm{CO}_{2}$ na produção e transporte do aglomerante (cimento)}

Os valores de emissão de $\mathrm{CO}_{2}$ no processo de produção do cimento considerado neste trabalho são oriundos do Segundo Inventário Brasileiro de Emissões e Remoções Antrópicas de Gases de
Efeito Estufa - Emissões de Gases de Efeito Estufa nos Processos Industriais - Produtos Minerais, Produção de Cimento, publicado pelo Ministério da Ciência e Tecnologia elaborado pelo Sindicato Nacional da Indústria do Cimento - SNIC e a Associação Brasileira de Cimento Portland ABCP no ano de 2010 (BRASIL, 2010).

O inventário apresenta que no ano de 2005, conforme Figura 5, para uma produção de 38.706.000 toneladas de cimento gerou-se a emissão de 14.349.000 toneladas de $\mathrm{CO}_{2}$, obtendose um fator de emissão de 0,371 toneladas de $\mathrm{CO}_{2} /$ tonelada de cimento produzido ou $0,371000 \mathrm{~kg}$ $\mathrm{CO}_{2} / \mathrm{kg}$ de cimento produzido.

Além da produção, também o transporte do cimento da fábrica até o local de utilização na central dosadora de concreto foi considerado, visto o consumo de óleo diesel durante a sua combustão emitir $\mathrm{CO}_{2}$. Após levantamentos, constatou-se que o cimento utilizado na produção do concreto vem da cidade de Rio Branco do Sul do estado do Paraná e emite o valor apresentado na Tabela 6. 
Tabela 4 - Cálculo da emissão de $\mathrm{CO}_{2}$ da matéria prima

\begin{tabular}{c|c|c|c|c|c}
\hline Matéria Prima & $\begin{array}{c}\text { Produção } \\
(\mathbf{k g} / \mathbf{m e ̂ s})\end{array}$ & $\begin{array}{c}\text { Consumo } \\
\text { Diesel } \\
(\mathbf{l} / \mathbf{m e ̂ s})\end{array}$ & $\begin{array}{c}\text { Cosumo } \\
\text { Diesel } \\
(\mathbf{l} / \mathbf{k g})\end{array}$ & $\begin{array}{c}\text { Emissão CO } \\
\text { Diesel } \\
(\mathbf{k g C O} / \mathbf{L})\end{array}$ & $\begin{array}{c}\text { Emissão } \\
\mathbf{C O}_{\mathbf{2}} \\
(\mathbf{k g C O} / \mathbf{k g})\end{array}$ \\
\hline Agregado Miúdo (areia natural) & 16.549 .000 & 22.000 & 0,001329 & 2,671 & 0,003550 \\
\hline
\end{tabular}

Tabela 5 - Cálculo da emissão de $\mathrm{CO}_{2}$ do transporte da matéria prima

\begin{tabular}{c|c|c|c|c|c}
\hline Matéria Prima & $\begin{array}{c}\text { Carga } \\
\text { Transportada } \\
(\mathbf{k g} / \text { viagem })\end{array}$ & $\begin{array}{c}\text { Consumo } \\
\text { Diesel } \\
(\mathbf{l} / \text { viagem })\end{array}$ & $\begin{array}{c}\text { Consumo } \\
\text { Diesel } \\
(\mathbf{l} / \mathbf{k g})\end{array}$ & $\begin{array}{c}\text { Emissão } \\
\mathbf{C O 2 ~ D i e s e l ~} \\
(\mathbf{k g C O 2} / \mathbf{l})\end{array}$ & $\begin{array}{c}\text { Emissão } \\
\mathbf{C O}_{\mathbf{2}} \\
(\mathbf{k g C O} / \mathbf{k g})\end{array}$ \\
\hline Agregado Miúdo (areia natural) & 28.000 & 250 & 0,008929 & 2,671 & 0,023849 \\
\hline
\end{tabular}

Figura 5 - Produção de cimento e emissões de $\mathrm{CO}_{2}$ no Brasil

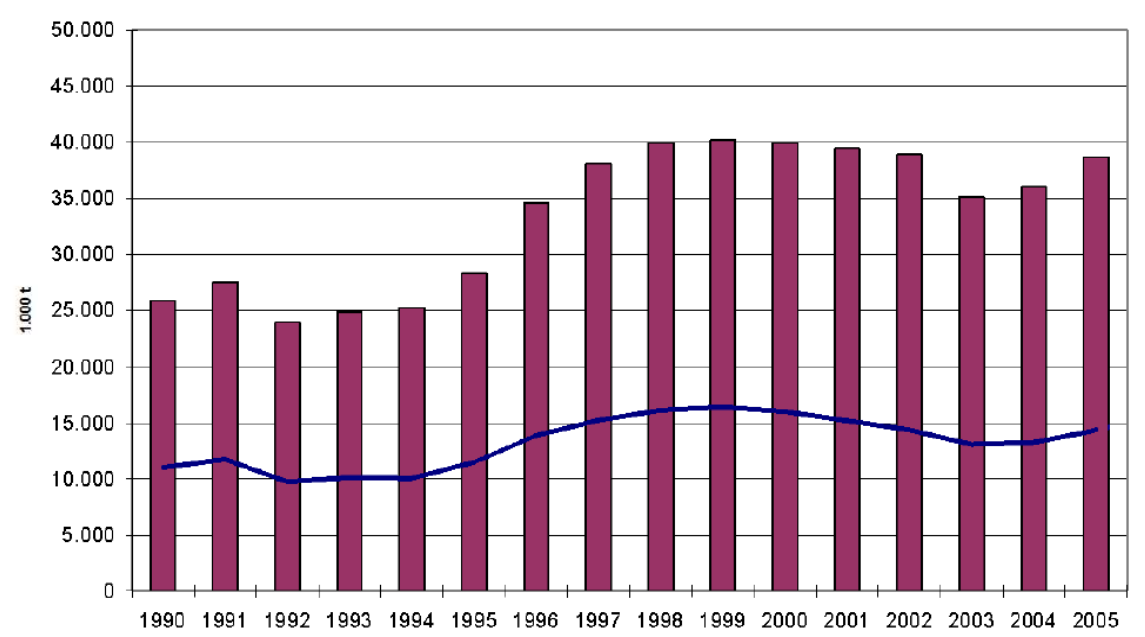

Fonte: segundo Inventário Brasileiro de Emissões e Remoções Antrópicas de Gases de Efeito Estufa - Produção de Cimento (BRASIL, 2010).

Nota: Legenda:

$\square$ Produção de cimento (mil ton); e

- Emissções absolutas (mil ton).

Tabela 6 - Cálculo da emissão de $\mathrm{CO}_{2}$ do transporte da matéria prima

\begin{tabular}{c|c|c|c|c|c}
\hline Matéria Prima & $\begin{array}{c}\text { Carga } \\
\text { Transportada } \\
(\mathbf{k g} / \text { viagem) }\end{array}$ & $\begin{array}{c}\text { Consumo } \\
\text { Diesel } \\
(\mathbf{l} / \text { viagem })\end{array}$ & $\begin{array}{c}\text { Consumo } \\
\text { Diesel } \\
(\mathbf{l} / \mathbf{k g})\end{array}$ & $\begin{array}{c}\text { Emissão CO } \mathbf{C O}_{\mathbf{2}} \\
\text { Diesel } \\
(\mathbf{k g C O} / \mathbf{l})\end{array}$ & $\begin{array}{c}\text { Emissão } \\
\mathbf{C O}_{\mathbf{2}} \\
(\mathbf{k g C O} / \mathbf{k g})\end{array}$ \\
\hline Aglomerante (cimento) & 32.000 & 580 & 0,018125 & 2,671 & 0,048412 \\
\hline
\end{tabular}

\section{Emissões $\mathrm{CO}_{2}$ na produção e transporte do concreto}

A central dosadora de concreto na qual foi realizado o levantamento possui clientes na cidade de Passo Fundo e região. As matérias primas, transportadas por caminhões até o pátio da empresa são armazenadas separadas em baias ao ar livre. O aglomerante, proveniente de empresa da cidade de Rio Branco do Sul no estado do Paraná, é recebido a granel através de caminhão, sendo armazenado em silo da central dosadora
Além das máquinas e equipamentos que constituem a central dosadora a estrutura da empresa é composta por laboratório responsável pelo controle tecnológico, escritório responsável pela área administrativa, pá carregadeira para movimentação das matérias primas no pátio, caminhões betoneira para o transporte do concreto até a obra, conforme ilustra a imagem da Figura 6, bombas que transportam o concreto horizontalmente ou verticalmente na obra até a fôrma e carro de apoio utilizado para o acompanhamento técnico nas obras. 
Após acompanhar o processo produtivo e realizar o levantamento de dados necessários para o estudo com a gerência da empresa, foram sistematizadas as informações, as quais são apresentadas nas Tabelas 7 e 8 .

\section{Análise dos dados levantados com avaliações e comparações dos resultados}

Apresentam-se na sequência os resultados, de maneira que possam ser verificadas as contribuições nas emissões de $\mathrm{CO}_{2}$ de cada matéria prima utilizada na produção do concreto, bem como a parcela de contribuição do processo de produção e transporte do concreto até a obra pela central dosadora de concreto.

\section{Emissões de $\mathrm{CO}_{2}$ das matérias primas}

Os resultados levantados e apresentados na Tabela 9 e na Figura 7 apresentam que a maior emissão das matérias primas em estudo tanto na fase de produção como na fase de transporte ocorre com o aglomerante (cimento). Verifica-se também que o agregado miúdo natural tem mais que $87 \%$ de suas emissões provenientes do seu transporte.

\section{Emissões de $\mathrm{CO}_{2}$ das matérias primas utilizadas na produção de um metro cúbico de concreto}

Com os dados obtidos nos levantamentos e apresentados anteriormente, foi realizada a quantificação das emissões das matérias primas para a composição de um metro cúbico de concreto, trabalhando-se com traços de resistência característica de 20 e $40 \mathrm{MPa}$.

Para o concreto com resistência característica de 20MPa foi efetuada a determinação das emissões de $\mathrm{CO}_{2}$ por metro cúbico de concreto. Os resultados obtidos, listados na Tabela 10, indicam que o aglomerante, apesar de ser o menor contribuinte em massa, é a matéria prima que produz maior emissão de $\mathrm{CO}_{2}$. Observa-se ainda que o agregado miúdo natural é a segunda matéria prima tanto em contribuição em massa como em emissões de $\mathrm{CO}_{2}$. Um comparativo das contribuições das matérias primas tanto em massa como em emissões de $\mathrm{CO}_{2}$ pode ser visualizado de forma mais clara com o auxílio da Figura 8.

Figura 6 - Carregamento das matérias primas no caminhão betoneira

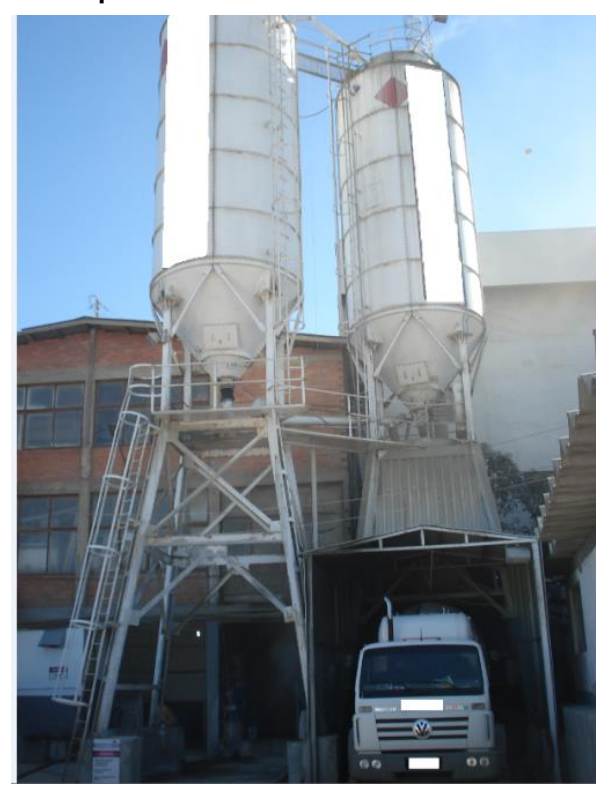

Tabela 7 - Produção e consumo de diesel por metro cúbico de concreto

\begin{tabular}{c|c|c|c|c|c}
\hline Material & $\begin{array}{c}\text { Produção } \\
\left(\mathbf{m}^{\mathbf{3}} \mathbf{m} \mathbf{m}\right)\end{array}$ & $\begin{array}{c}\text { Consumo Diesel } \\
\text { Pá Carregadeira } \\
\left(\mathbf{l} / \mathbf{m}^{\mathbf{3}}\right)\end{array}$ & $\begin{array}{c}\text { Consumo Diesel } \\
\text { Caminhão Betoneira } \\
\left(\mathbf{l} / \mathbf{m}^{\mathbf{3}}\right)\end{array}$ & $\begin{array}{c}\text { Consumo } \\
\text { Diesel Bomba } \\
\left(\mathbf{l} / \mathbf{m}^{\mathbf{3}}\right)\end{array}$ & $\begin{array}{c}\text { Consumo Gasolina A } \\
\text { Carro Apoio } \\
\left(\mathbf{l} / \mathbf{m}^{\mathbf{3}}\right)\end{array}$ \\
\hline Concreto & 3.000 & 0,21 & 2,37 & 0,85 & 0,10 \\
\hline
\end{tabular}


Tabela 8 - Cálculo das emissões de $\mathrm{CO}_{2}$ por metro cúbico de concreto

\begin{tabular}{c|c|c|c|c|c}
\hline Material & $\begin{array}{c}\text { Emissão CO } \\
\text { Diesel } \\
\left(\mathbf{k g C O}_{2} / \mathbf{l}\right)\end{array}$ & $\begin{array}{c}\text { Emissão CO } \mathbf{C O}_{2} \\
\text { Pá Carregadeira } \\
\left(\mathbf{k g C O}_{2} / \mathbf{m}^{\mathbf{3}}\right)\end{array}$ & $\begin{array}{c}\text { Emissão } \mathbf{C O}_{2} \\
\mathbf{C a m i n h a ̃ o ~ B e t o n e i r a ~} \\
\left(\mathbf{k g C O}_{2} / \mathbf{m}^{\mathbf{3}}\right)\end{array}$ & $\begin{array}{c}\text { Emissão CO } \\
\text { Bomba } \\
\left(\mathbf{k g C O}_{2} / \mathbf{m}^{\mathbf{3}}\right)\end{array}$ & $\begin{array}{c}\text { Emissão } \mathbf{C O}_{2} \\
\text { Carro Apoio } \\
\left(\mathbf{k g C O}_{2} / \mathbf{m}^{\mathbf{3}}\right)\end{array}$ \\
\hline Concreto & 2,671 & 0,560910 & 6,330270 & 2,270350 & 0,226900 \\
\hline
\end{tabular}

Tabela 9 - Emissões de $\mathrm{CO}_{2}$ da extração/produção e transporte das matérias primas

\begin{tabular}{c|c|c|c|c|c}
\hline Matéria Prima & $\begin{array}{c}\text { Extração/Produção } \\
\mathbf{K g C O} / \mathbf{K g}\end{array}$ & $\begin{array}{c}\text { Transporte } \\
\mathbf{K g C O}_{2} / \mathbf{K g}\end{array}$ & $\begin{array}{c}\text { Total } \\
\mathbf{K g C O} / \mathbf{K g}\end{array}$ & $\begin{array}{c}\text { Extração/Produção } \\
\mathbf{\%}\end{array}$ & $\begin{array}{c}\text { Transporte } \\
\text { \% }\end{array}$ \\
\hline Agregado Graúdo & 0,004007 & 0,000580 & 0,004587 & 87,36 & 12,64 \\
\hline $\begin{array}{c}\text { Agregado Miúdo } \\
\text { Natural }\end{array}$ & 0,003550 & 0,023849 & 0,027399 & 12,96 & 87,04 \\
\hline $\begin{array}{c}\text { Agregado Miúdo } \\
\text { Britagem }\end{array}$ & 0,004007 & 0,000636 & 0,004643 & 86,30 & 13,70 \\
\hline $\begin{array}{c}\text { Aglomerante } \\
\text { (cimento) }\end{array}$ & 0,371000 & 0,048412 & 0,419412 & 88,46 & 11,64 \\
\hline
\end{tabular}

Figura 7 - Porcentagens de emissões de $\mathrm{CO}_{2}$ da extração/produção e transporte

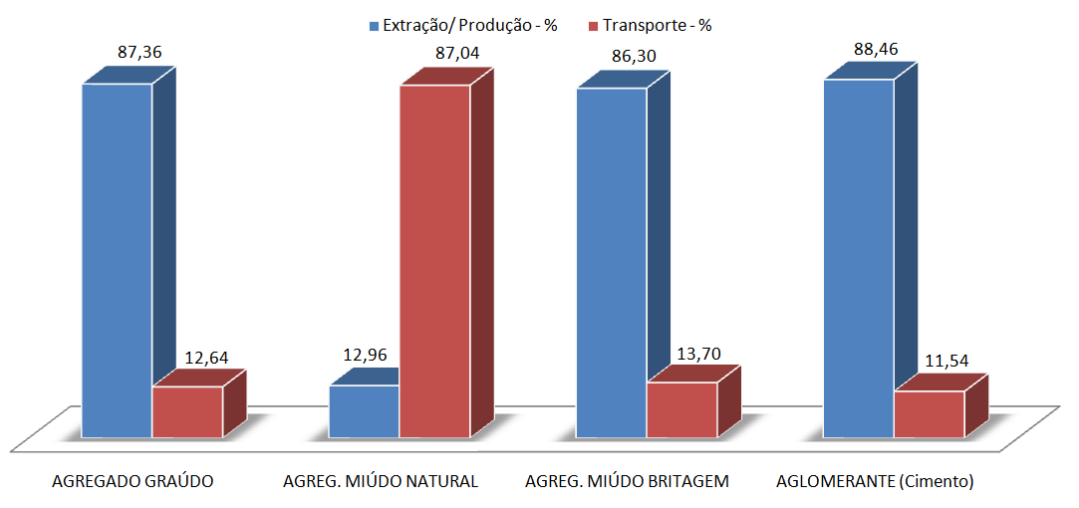

Tabela 10 - Emissões de $\mathrm{CO}_{2}$ por metro cúbico para o concreto com traço de $20 \mathrm{MPa}$

\begin{tabular}{c|c|c|c|c}
\hline Matéria Prima & $\begin{array}{c}\text { Quantidade } \\
\mathbf{K g} / \mathbf{m}^{3}\end{array}$ & $\begin{array}{c}\text { Emissões } \\
\text { Ext/Produção } \\
\mathbf{K g C O} \mathbf{K g}\end{array}$ & $\begin{array}{c}\text { Emissões } \\
\text { Transporte } \\
\mathbf{K g C O}_{\mathbf{2}} / \mathbf{K g}\end{array}$ & $\begin{array}{c}\text { Emissões } \\
\text { Totais } \\
\mathbf{K g} / \mathbf{m}^{\mathbf{3}}\end{array}$ \\
\hline Agregado Graúdo & 896,90 & 0,004007 & 0,000580 & 4,114080 \\
\hline Agregado Miúdo Natural & 535,93 & 0,003550 & 0,023849 & 14,683946 \\
\hline Agregado Miúdo Britagem & 437,65 & 0,004007 & 0,000636 & 2,032009 \\
\hline Aglomerante (cimento) & 221,00 & 0,371000 & 0,048412 & 92,690052 \\
\hline Emissão Total (Traço 20 MPa): & \multicolumn{4}{|c|}{$\mathbf{1 1 3 , 5 2 0 0 8 7} \mathbf{K g C O}_{\mathbf{2}} / \mathbf{m}^{\mathbf{3}}$ Concreto } \\
\hline
\end{tabular}

Figura 8 - Comparativo das contribuições por metro cúbico - traço $20 \mathrm{MPa}$

- EM MASSA $\left(\mathrm{Kg} / \mathrm{m}^{3}\right)$

- EM EMISSÕES $\left(\mathrm{Kg} \mathrm{CO2} / \mathrm{m}^{3}\right)$

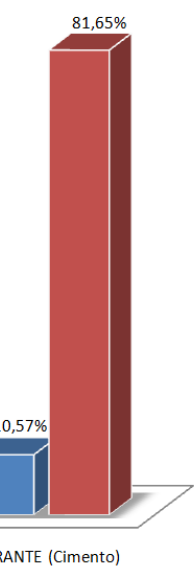

44 Santoro, J. F.; Kripka, M. 
Ao analisar as contribuições na composição do concreto com resistência característica de $40 \mathrm{MPa}$, pode-se verificar na Tabela 11, após os cálculos realizados, que novamente a matéria prima aglomerante (cimento) é o menor contribuinte em massa e é a que mais emite $\mathrm{CO}_{2}$ para a produção de um metro cúbico de concreto, conforme Figura 9. Da mesma forma, verifica-se que o agregado miúdo natural apresenta-se em segundo lugar tanto em contribuição em massa como em emissões de $\mathrm{CO}_{2}$.

Quando comparadas as resistências, constata-se que o concreto de $40 \mathrm{MPa}$ tem uma emissão total $28,31 \%$ maior que o concreto de $20 \mathrm{MPa}$. Tal fato se deve pelo consumo de aglomerante por metro cúbico ser $33,63 \%$ maior no concreto de $40 \mathrm{MPa}$ e o mesmo ser o maior emissor de $\mathrm{CO}_{2}$ das matérias primas constituintes do concreto. Cabe destacar que as emissões do aglomerante durante sua fase de produção foram obtidas a partir de valores médios retirados da literatura. Assim, uma eventual variação no valor considerado, decorrente do tipo de cimento e do processo produtivo específico de cada cimenteira, podem acarretar numa variação no percentual obtido.

Definidas as composições das matérias primas de um metro cúbico de concreto, apresentam-se no gráfico da Figura 10 os percentuais de contribuição de cada fase dos processos de extração/produção e transporte das mesmas. Constata-se que o percentual de contribuição do transporte é maior para a produção de um metro cúbico do concreto com traço de $20 \mathrm{MPa}$, o qual contribui com $21,38 \%$ das emissões totais de $\mathrm{CO}_{2}$. A contribuição do transporte para o concreto com traço de $40 \mathrm{MPa}$ diminui em virtude do maior consumo de aglomerante e este ter um percentual elevado de emissões na fase de extração/produção em relação ao transporte se comparado com as outras matérias primas.

A Figura 11 apresenta as contribuições de emissões de cada material, separadamente, para a produção de um metro cúbico de concreto, considerando-se os traços para as resistências características de 20 e $40 \mathrm{MPa}$.

Tabela 11 - Emissões de $\mathrm{CO}_{2}$ por metro cúbico para o concreto com traço de $40 \mathrm{MPa}$

\begin{tabular}{|c|c|c|c|c|}
\hline Matéria Prima & $\begin{array}{c}\text { Quantidade } \\
\mathrm{Kg} / \mathrm{m}^{3}\end{array}$ & $\begin{array}{c}\text { Emissões } \\
\text { Ext/Produção } \\
\mathrm{KgCO}_{2} / \mathrm{Kg} \\
\end{array}$ & $\begin{array}{c}\text { Emissões } \\
\text { Transporte } \\
\mathrm{KgCO}_{2} / \mathrm{Kg} \\
\end{array}$ & $\begin{array}{c}\text { Emissões } \\
\text { Totais } \\
\mathrm{Kg} \mathrm{CO}_{2} / \mathrm{m}^{3} \\
\end{array}$ \\
\hline Agregado Graúdo & 997,61 & 0,004007 & 0,000580 & 4,576037 \\
\hline Agregado Miúdo Natural & 451,92 & 0,003550 & 0,023849 & 12,382156 \\
\hline Agregado Miúdo Britagem & 370,52 & 0,004007 & 0,000636 & 1,720324 \\
\hline Aglomerante (cimento) & 333,00 & 0,371000 & 0,048412 & 139,664196 \\
\hline Emissão Total (Traço 40 MPa): & \multicolumn{4}{|c|}{$158,342714 \mathrm{KgCO} / \mathrm{m}^{3}$ Concreto } \\
\hline
\end{tabular}

Figura 9 - Comparativo das contribuições por metro cúbico - traço $40 \mathrm{MPa}$

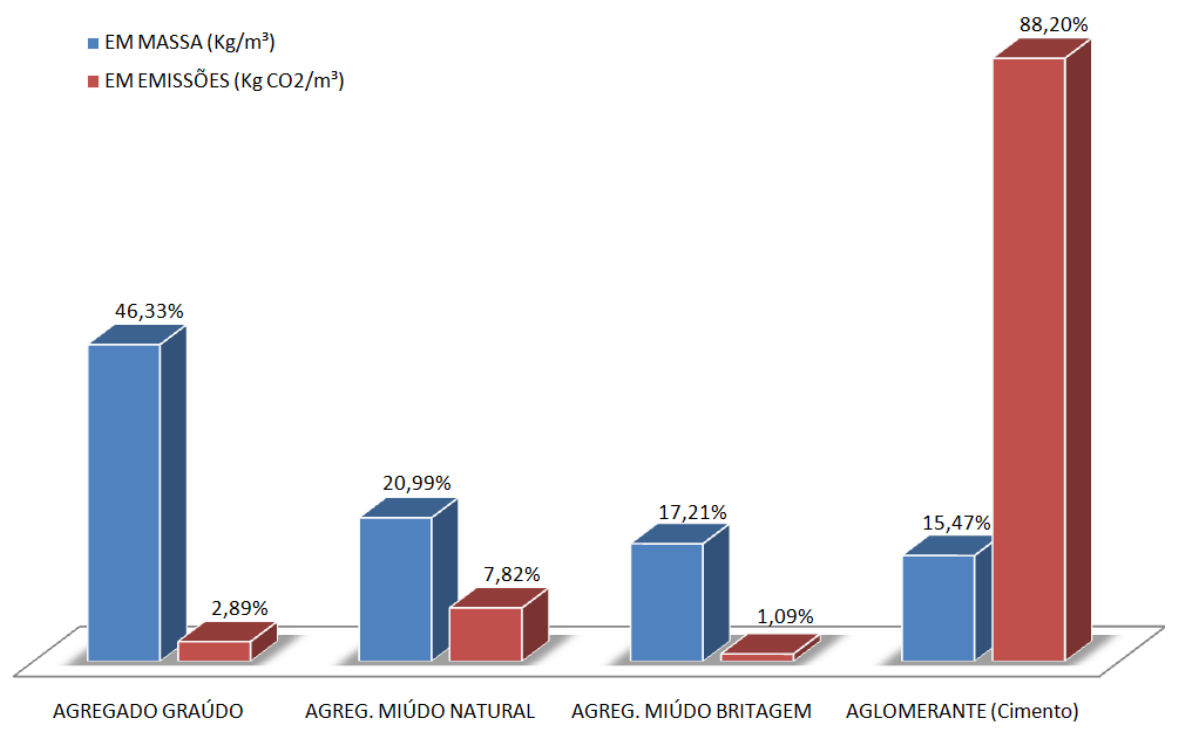


Figura 10 - Contribuições nas emissões de $\mathrm{CO}_{2}$ por metro cúbico de concreto

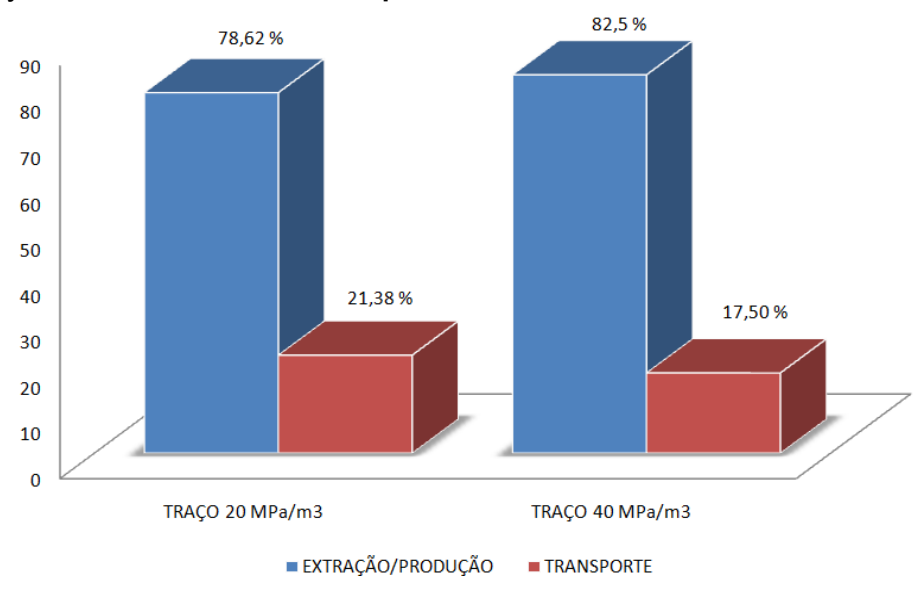

Figura 11 - Contribuições nas emissões de $\mathrm{CO}_{2}$ na produção de um metro cúbico de concreto

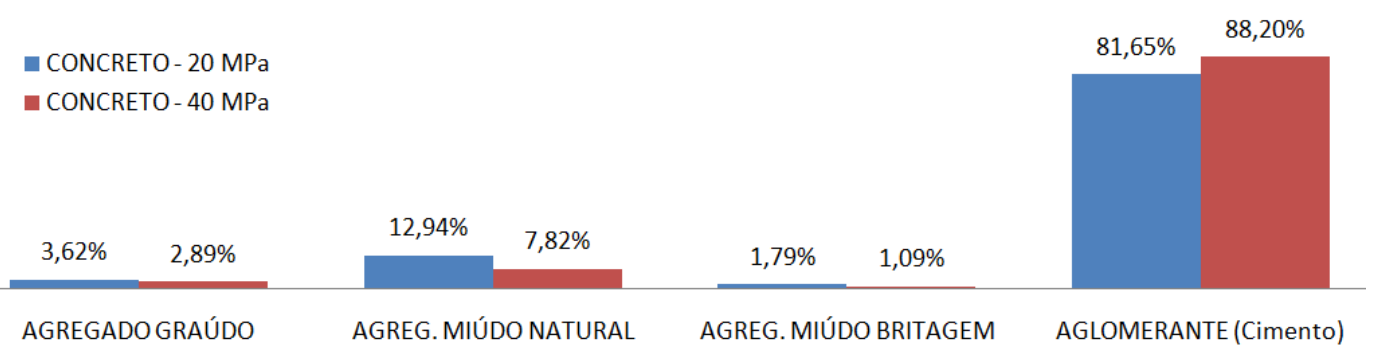

\section{Emissões de $\mathrm{CO}_{2}$ nos processos de produção e transporte até a obra, de um metro cúbico de concreto pela central dosadora}

Além das emissões de $\mathrm{CO}_{2}$ das matérias primas utilizadas no processo, também foram quantificadas as emissões por parte da central dosadora de concreto, sendo os valores correspondentes apresentados na Tabela 12 e 13 . Como referência, considerou-se uma obra fictícia situada no centro da cidade de Passo Fundo. Na Tabela 13, a primeira coluna refere-se à movimentação das matérias primas no pátio da central dosadora, enquanto que a movimentação na obra se refere ao transporte na própria obra, pela movimentação horizontal ou vertical do concreto pelas bombas. A partir do gráfico da Figura 12 verifica-se que a maior parcela de contribuição das emissões totais de $\mathrm{CO}_{2}$ destas etapas do processo advém do transporte do concreto até a obra, seguida da movimentação na própria obra.

Quando comparada a contribuição das emissões destas etapas do processo em conjunto com as etapas de produção e transporte das matérias primas, consta-se conforme Figura 13 que, o concreto com $20 \mathrm{MPa}$ de resistência característica tem um contribuição maior do que o concreto com resistência característica de $40 \mathrm{MPa}$.

\section{Emissões totais de $\mathrm{CO}_{2}$ na produção de um metro cúbico de concreto, com resistência características diferentes}

Os levantamentos obtidos no estudo das emissões na extração, produção e transporte das matérias primas, como também na produção e transporte do concreto até a obra, apresentaram que o concreto com resistência característica de $40 \mathrm{MPa}$, tem uma emissão por metro cúbico $26,72 \%$ maior conforme apresentado na Tabela 14.

\section{Considerações finais}

Grande parte das empresas produtoras de materiais de construção civil já possuem ações minimizadoras fazendo parte do cotidiano, seja pela conscientização espontânea ou por força da legislação vigente.

Levar esta cultura para todas as empresas produtoras de materiais de construção civil sejam de grande ou pequeno porte irá contribuir em muito para a minimização dos impactos ambientais gerados pelas mesmas. No estudo e análise dos impactos ambientais, um tema importante é negligenciado, o de como os arquitetos e engenheiros podem implementar essas considerações durante a etapa de projeto. 
Tabela 12 - Consumo de combustível por metro cúbico de concreto pela central dosadora

\begin{tabular}{c|c|c|c|c}
\hline MATERIAL & $\begin{array}{c}\text { DIESEL } \\
\text { PÁ CARREGADEIRA } \\
\left(\mathbf{l}_{\left.\mathbf{1} \mathbf{m}^{\mathbf{3}}\right)}\right.\end{array}$ & $\begin{array}{c}\text { DIESEL } \\
\text { CAMINHÃO BETONEIRA } \\
\left(\mathbf{1} / \mathbf{m}^{\mathbf{3}}\right)\end{array}$ & $\begin{array}{c}\text { DIESEL } \\
\text { BOMBA } \\
\left(\mathbf{l} / \mathbf{m}^{\mathbf{3}}\right)\end{array}$ & $\begin{array}{c}\text { GASOLINA A } \\
\text { CARO APOIO } \\
\left(\mathbf{l} / \mathbf{m}^{\mathbf{3}}\right)\end{array}$ \\
\hline CONCRETO & 0,21 & 2,37 & 0,85 & 0,10 \\
\hline
\end{tabular}

Tabela 13 - Emissões de $\mathrm{CO}_{2}$ nos processos da central dosadora de concreto

\begin{tabular}{c|c|c|c|c}
\hline $\begin{array}{c}\text { MOVIMENTAÇÃO } \\
\text { MATÉRIAS PRIMAS } \\
\text { Kg CO } \mathbf{~ O}_{2} / \mathbf{m}^{3}\end{array}$ & $\begin{array}{c}\text { TRANSPORTE } \\
\text { ATÉ A OBRA } \\
\mathrm{Kg} \mathrm{CO}_{2} / \mathbf{m}^{3}\end{array}$ & $\begin{array}{c}\text { MOVIMENTAÇÃO } \\
\text { NA OBRA } \\
\mathrm{Kg} \mathrm{CO}_{2} / \mathbf{m}^{\mathbf{3}}\end{array}$ & $\begin{array}{c}\text { VEÍCULO DE } \\
\text { APOIO } \\
\mathrm{Kg} \mathrm{CO}_{2} / \mathbf{m}^{\mathbf{3}}\end{array}$ & $\begin{array}{c}\text { EMISSÕES } \\
\text { TOTAIS } \\
\mathrm{Kg} \mathrm{CO}_{2} / \mathbf{m}^{\mathbf{3}}\end{array}$ \\
\hline 0,560910 & 6,330270 & 2,270350 & 0,226900 & 9,388430 \\
\hline
\end{tabular}

Figura 12 - Contribuições de emissões $\mathrm{CO}_{2}$ nos processos da central dosadora de concreto

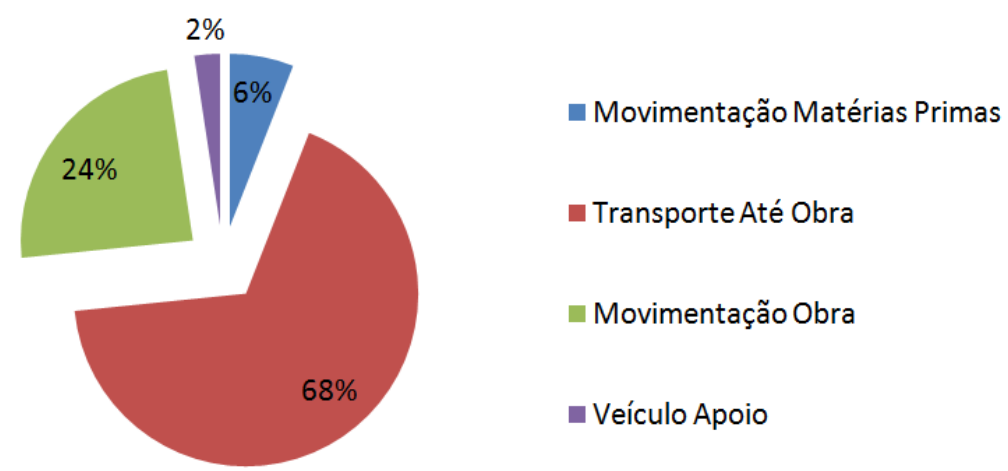

Figura 13 - Contribuições nas emissões totais de $\mathrm{CO}_{2}$ por metro cúbico de concreto

\section{Concreto $20 \mathrm{MPa}$}

• Extração/Produção e Transporte Matérias Primas

- Produção e Transporte Concreto

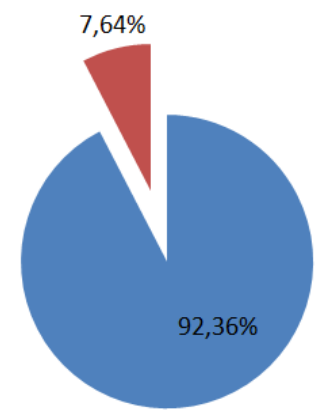

Concreto $40 \mathrm{MPa}$

— Extração/Produção e Transporte Matérias Primas

- Produção e Transporte Concreto

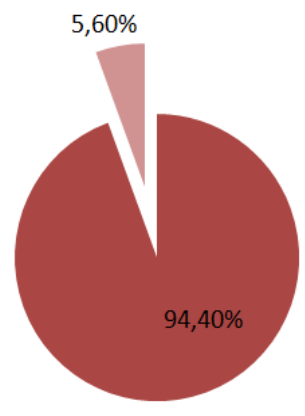

Tabela 14 - Emissões de $\mathrm{CO}_{2}$ por metro cúbico de concreto

\begin{tabular}{c|c}
\hline Resistência Característica & Emissão de $\mathbf{K g C O}_{\mathbf{2}} / \mathbf{m}^{\mathbf{3}}$ \\
\hline $20 \mathrm{MPa}$ & 122,908517 \\
$40 \mathrm{MPa}$ & 167,731144 \\
\hline
\end{tabular}

O presente trabalho propôs a determinação de parâmetros de emissões de $\mathrm{CO}_{2}$ da produção e transporte das matérias primas e da produção e transporte do concreto até a obra, para serem utilizados no projeto de estruturas de concreto levando-se em conta, além da questão econômica, também o impacto ambiental. Com esse objetivo, num primeiro momento determinou-se a região de estudo, os responsáveis pela extração e produção, bem como pelos deslocamentos das matérias primas até a sua utilização. Após, foram realizadas as visitas nos locais, coletas de dados e 
determinação dos valores relativos às emissões de dióxido de carbono de cada matéria prima.

Avaliando-se os resultados obtidos, conclui-se que produzindo um concreto com resistência característica maior se estará emitindo uma maior quantidade de $\mathrm{CO}_{2}$ no meio ambiente, principalmente pelo fato de que o cimento, maior emissor dentre as matérias primas, estará presente em maior quantidade. Destaca-se, no entanto, que concretos de maior resistência serão empregados em volumes menores. Assim, conclusões definitivas só podem ser obtidas após o dimensionamento de cada estrutura ou elemento, considerando também a quantidade de aço e suas correspondentes emissões.

Por ter sido considerada, no ciclo de vida, apenas a fase de pré-uso, não foram considerados os impactos gerados pelas fôrmas, uma vez que estas não integram a estrutura definitiva e, portanto, a fase de efetiva utilização da edificação.

Em relação ao transporte, constatou-se que as emissões de $\mathrm{CO}_{2}$ desta etapa são significativas, pelas longas distâncias percorridas por duas das quatro matérias primas utilizadas na produção do concreto. $\mathrm{O}$ agregado miúdo natural (areia) é o que possui a maior contribuição do transporte no seu total de emissões.

Não é de conhecimento dos autores a existência de estudo semelhante ao aqui apresentado, nem de valores de emissões de regiões próximas que possam ser empregados para uma análise confiável. Destaca-se que os resultados obtidos se referem a procedimentos e equipamentos adotados por uma empresa específica, e que podem variar de acordo com o local e a metodologia considerados. No entanto, apesar de direcionada à região norte do Rio Grande do Sul, entende-se que a metodologia empregada pode ser facilmente adaptada a outras realidades.

\section{Referências}

AGUIRRE, A. B.; HENNIES, W. T. Logística Para Agregados (Brita e Areia) em Grandes Centros Urbanos. Revista Escola de Minas, v. 63, n. 4, p. 639-643, 2010.

ALSHAMRANI, O. S.; GALAL, K.; ALKASS, S. Integrated LCA-LEED Sustainability Assessment Model for Structure and Envelope Systems of School Building. Journal Building and Environment, v. 80, p. 61-70, oct. 2014.

ASSOCIAÇÃO BRASILEIRA DE NORMAS TÉCNICAS. NBR 14040: gestão ambiental: avaliação do ciclo de vida: princípios e estrutura. Rio de Janeiro, 2009.
BRASIL. Ministério da Ciência e Tecnologia. Segundo Inventário Brasileiro de Emissões e Remoções Antrópicas de Gases de Efeito Estufa: rocessos industriais, produtos minerais, produção de cimento. Brasília, DF, 2010.

BRASIL. Ministério do Meio Ambiente. Primeiro Inventário Nacional de Emissões Atmosféricas por Veículos Automotores Rodoviários. Brasília, DF, 2011.

CABEZA, L. F. et al. Life Cycle Assessment (LCA) and Life Cycle Energy Analysis (LCEA) of Buildings and the Building Sector: a review. Journal Renewable and Sustainable Energy Reviews, v. 29, p. 394-416, 2014.

CARVALHO, M. B. M. Impactos e Conflitos da Produção de cimento no Distrito Federal.

Brasília, 2008. 162 f. Dissertação (Mestrado em Desenvolvimento Sustentável) - Universidade de Brasília, Brasília, 2008.

EDVARDSEN, C.; TOLLOSE, K. Environmentally "Green" Concrete Structures. In: FIB SYMPOSIUM CONCRETE AND ENVIRONMENT, Berlin, 2001. Proceedings... Berlin, 2001.

GOOGLE MAPS. [Como chegar]. Disponível em: <https://maps.google.com.br/>. Acesso em: 06 jan. 2015.

GUARDIGLI, L.; MONARI, F; BRAGADIN, M. A. Assessing Environmental Impact of Green Buildings Through LCA Methods: a comparison between reinforced concrete and wood structures in the European context. In: INTERNATIONAL CONFERENCE ON GREEN BUILDINGS AND SUSTAINABLE CITIES, 21., 2011.

Proceedings... 2011 .

HAMMOND, G. P.; JONES, C. I. Embodied Energy and Carbon in Construction Materials. Institution of Civil Engineers - Energy, v. 161, n 2, p. 87-98, 2008.

INTERCEMENT. Relatório Anual 2010: como funciona o mercado cimenteiro. Disponível em: <http://www.intercement.com/RS2010/pt/comofunciona-o-mercado-cimenteiro/>. Acesso em: 18 jun. 2015.

JI, C.; HONG, T.; PARK, H. S.Comparative Analysis of Decision-Making Methods for Integrating Cost and $\mathrm{CO}_{2}$ Emission: focus on building structural design. Energy and Buildings, v. 72, p. 86-194, 2014.

JOHN, V. M.; OLIVEIRA, D. P.; LIMA, J. A. R. Levantamento do Estado da arte: seleção de materiais. Projeto tecnologias para construção. São Paulo: FINEP, 2007. Habitacional mais sustentável. 
MEDEIROS, G. F.; KRIPKA, M. Optimization of Reinforced Concrete Columns According to Different Environmental Impact Assessment Parameters. Engineering Structures, v. 59, p. 185-194, 2014.

MILLER, D. et al. Environmental Impact Assessment of Post Tensioned and Reinforced Concrete Slab Construction. In: B. SAMALI, M.; ATTARD, M.; SONG, C. (Eds.). Proceedings of the $22^{\text {nd }}$ Australasian Conference on the Mechanics of Structures and Materials: From Materials to Structures: Advancement through Innovation. London: Taylor \& Francis Group, 2013.

\section{NATIONAL READY MIXED CONCRETE} ASSOCIATION. Concrete $\mathbf{C O}_{2}$ Fact Sheet. Jun. 2008. Disponível em:

<www.nrmca.org/greenconcrete/concrete\%20co2 $\% 20$ fact $\% 20$ sheet $\% 20$ june $\% 202008$.pdf $>$. Acesso em: 18 jun. 2015.

OCHSENDORF, J. et al. Methods, Impacts, and Opportunities in the Concrete Building Life Cycle. Cambridge: Department of Civil and Environmental Engineering of Massachusetts, Institute of Technology, 2011.

OLIVEIRA, A. S. Análise Ambiental da Viabilidade de Seleção de Produtos da Construção Civil Através da ACV e do Software BEEs 3.0. Porto Alegre, 2007. Dissertação (Mestrado em Engenharia: Engenharia civil) - Escola de Engenharia, Universidade Federal do Rio Grande do Sul, Porto Alegre, 2007.

PASSER, A. et al. Life Cycle Assessment of Buildings Comparing Structural Steelwork With Other Construction Techniques. In:

INTERNATIONAL CONFERENCE ON LIFE

CYCLE MANAGEMENT, 3., Zurich, 2007.

Proceedings... Zurich: University of Zurich, 2007.
PAYÁ-ZAFORTEZA, I. et al. $\mathrm{CO}_{2}$-Optimization of Reinforced Concrete Frames by Simulated Annealing. Engineering Structures, v. 31, n. 7, p. 1501-1508, 2009.

POMMER, K.; PADE, C. Guidelines: uptake of carbon dioxide in the life cycle inventory of concrete. 2005. Disponível em:

<http://www.nordicinnovation.org/Global/_Public ations/Reports/2005/03018_guidelines_-

_uptake_of_carbon_dioxide_in_the_life_cycle_inv entory_of_concrete.pdf $>$. Acesso em: 07 jan. 2016.

PULLEN, S. et al. Minimising the Impact of Resource Consumption in the Design and Construction of Buildings. In: ANNUAL CONFERENCE OF THE ARCHITECTURAL SCIENCE ASSOCIATION, Queensland, 2012. Proceedings... Queensland, 2012.

SOUZA, A. Avaliação do Ciclo de Vida da Areia em Mineradora de Pequeno Porte, na Região de São José do Rio Preto - SP. São Carlos, 2012. 121 f. Dissertação (Mestrado em Engenharia Urbana) - Escola de Engenharia, Universidade Federal de São Carlos, São Carlos, 2012.

TAKANO, A. et al. Comparison of Life Cycle Assessment Databases: a case study on building assessment. Journal Building and Environment, v. 79, p. 20-30, 2014.

YEO, D.; GABBAI R. D. Sustainable Design of Reinforced Concrete Structures Through Embodied Energy Optimization. Energy and Buildings, v. 43, n. 8, p. 2028-2033, 2011.

\section{Jair Frederico Santoro}

Departamento de Ensino | Instituto Federal Sul-Rio-Grandense | Estrada Perimetral Leste, 150 | Passo Fundo - RS Brasil | CEP $99064-440$ | Tel.: (54) 3311-2916 | E-mail: jj.santoro@yahoo.com.br

\section{Moacir Kripka}

Programa de Pós-graduação em Engenharia Civil e Ambiental | Universidade de Passo Fundo | CEP 99001-970 | Tel.: (54)3316-8203 | E-mail: mkripka@upf.br

\section{Revista Ambiente Construído}

Associação Nacional de Tecnologia do Ambiente Construído

Av. Osvaldo Aranha, $99-3^{\circ}$ andar, Centro

Porto Alegre - RS - Brasil

CEP $90035-190$

Telefone: +55 (51) 3308-4084

Fax: +55 (51) 3308-4054

www.seer.ufrgs.br/ambienteconstruido

E-mail: ambienteconstruido@ufrgs.br 